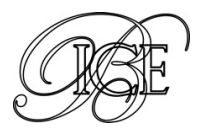

$M^{a}$ de la Palma Gómez-Calero Valdés*

María del P. Pablo-Romero Gil-Delgado*

Javier Sánchez Rivas*

\title{
ANÁLISIS DE LA DEMANDA INTERNACIONAL DE TURISMO EN ESPAÑA EN EL PERIODO 2001-2013 El turismo cultural
}

El objetivo del trabajo es profundizar en el conocimiento de la demanda de turismo en España. Para ello el trabajo se centra en el turismo receptor en general y en el turismo cultural en particular. El análisis se realiza a partir de los datos que ofrecen las fuentes estadísticas oficiales de ámbito nacional. La principal conclusión es la clara aportación de este sector al producto interior bruto de España y la creciente importancia en nuestro país de nuevas tipologías de turismo sensibilizadas con el medio ambiente, como es el turismo cultural.

Palabras clave: llegadas, gasto, estancia media, motivos, actividades culturales, medioambiente. Clasificación JEL: E17, O52, Z10.

\section{Introducción}

El turismo se viene configurando como una de las principales ramas de la actividad económica en España y a nivel internacional. Según la información facilitada por la Organización Mundial del Turismo (Barómetro OMT, 2015), para el año 2014 el número de llegadas de turistas internacionales a nivel mundial alcanzó un total de 1.138 millones de personas, lo que supuso un crecimiento del 4,7 por 100 respecto al año anterior. Igualmente, en el ámbito nacional esa importancia del turismo, como generador de riqueza y empleo, queda refrendada con las últimas estimaciones aportadas por la Cuenta Satélite del Turismo de España (CSTE), según las cuales, y para el año 2012, la actividad turística aportó el 10,9 por 100 del producto interior

\footnotetext{
* Departamento de Análisis Económico y Economía Política. Facultad de Ciencias Económicas y Empresariales. Universidad de Sevilla.

Versión de diciembre de 2015.
}

bruto (PIB) y generó el 11,9 por 100 del empleo total de nuestro país (INE, CSTE, Base 2008). Ello pone de manifiesto la capacidad de recuperación y evolución del turismo como rama de la actividad económica.

El objetivo de este trabajo es analizar la demanda de turismo internacional en España, con especial referencia a la demanda de turismo cultural, a partir de la información estadística facilitada por las fuentes oficiales. El estudio contribuye a poner de manifiesto la capacidad de recuperación y evolución del turismo como rama de la actividad económica, lo que adquiere una importancia aún mayor si se enmarca todo ello en un contexto nacional e internacional que se ha venido caracterizando por la intensa crisis económica.

Para ello, este trabajo se estructura del siguiente modo. Tras este apartado de introducción, el segundo apartado valora el turismo receptor que llega a nuestro país en función de la aportación de sus diferentes componentes al PIB, para el periodo $D$ 
2000-2012, a partir de la información ofrecida por la CSTE. En el tercer apartado se analizan las llegadas de turistas internacionales a España para los años 2001 a 2013, y el gasto que esos turistas realizaron en nuestro país en los años 2004 a 2013. El cuarto apartado se centra en los datos relativos al turismo cultural. Este apartado se fundamenta en el hecho de que España es un país eminentemente receptor de turismo internacional y en que la preocupación por la sostenibilidad del medio ambiente está ganando mayor peso entre los turistas internacionales que llegan a nuestro país. Dentro de esta tendencia ocupa un puesto importante el turismo cultural, cuyo estudio se realiza para el periodo 2005 a 2013. En el quinto apartado se concluye.

\section{Aportación del turismo al producto interior bruto de la economía española (2000-2012)}

El impacto económico del turismo en una economía queda constatado cuando se toma como indicador la aportación de la actividad turística al $\mathrm{PIB}$, en base a la información suministrada por la Cuenta Satélite del Turismo, que es la forma más completa de medir ese impacto (Naciones Unidas, Organización Mundial del Turismo, Comisión de las Comunidades Europeas, Eurostat, Organización de Cooperación y Desarrollo Económicos, 2010)ํ. El Gráfico 1 muestra la aportación del turismo al PIB español, de acuerdo con la CSTE. Esta participación del turismo en el PIB se mantiene en promedio durante el periodo estudiado en torno al 10,5 por 100, con unos valores máximo y mínimo de un 11,6 por 100 y de un 10 por 100 , que corresponden a los años 2001 y 2009 , respectivamente. A partir del año 2001, la evolución de la contribución de la

La Cuenta Satélite del Turismo: recomendaciones sobre el marco conceptual, 2008, ofrece las recomendaciones conceptuales comunes para la concepción de la Cuenta Satélite del Turismo. La Organización Mundial de Turismo invita a los países a elaborar, en base a esas recomendaciones, sus propias estadísticas de turismo (Naciones Unidas, Organización Mundial del Turismo, 2010). demanda turística al PIB ha seguido una senda decreciente que se prolonga hasta el año 2009 inclusive, en consonancia con la evolución general de la economía española e internacional, con la sola excepción del año 2006 en que alcanzó los 106.374,2 millones de euros, lo que supuso contribuir con un 10,9 por 100 al PIB. Durante los años de desaceleración de la demanda turística, los descensos más acusados se registraron en los años 2002 y 2008 , descensos que representaron una variación negativa de 0,4 décimas respecto al año precedente para cada uno de ellos. También ha sido continuamente decreciente la contribución del turismo receptor al PIB, pasando de ser un 5,8 por 100 en el año 2000 a ser tan sólo de un 4,3 por 100 en el año 2009, lo que ha supuesto una reducción de 1,5 puntos porcentuales. Mientras que la aportación del resto de componentes se ha mantenido levemente creciente hasta el año 2007 que alcanzó el 1,7 por 100 del PIB, para cambiar de tendencia en los años 2008 y 2009 en los que su peso en el PIB pasó a ser un 5,8 y un 5,7 por 100, respectivamente.

Tras el punto de inflexión que supone el año 2009, el peso de la demanda turística, en consonancia con una evolución general más favorable de la economía española y de su entorno internacional, incrementa su contribución al PIB, que pasó de ser un 10,1 por 100 en 2009 a un 10,9 por 100 en 2012. En estos años de ascenso, y a diferencia de la fase anteriormente comentada, fue la contribución del consumo turístico receptor al PIB la que mostró una mayor recuperación, pasando su crecimiento interanual de ser un 4,3 por 100 en el año 2009 a un 5,1 por 100 en 2012, mientras que la aportación del resto de componentes se mantuvo en un 5,9 por 100, salvo en el último año del periodo que descendió hasta un 5,8 por 100.

A partir del año 2009 comienza una tendencia de consolidación de la recuperación de la actividad turística, que queda confirmada por los datos conocidos hasta el momento sobre flujos turísticos para el año 2013. Esta consolidación de la recuperación de la actividad turística, debida en buena $\triangleright$ 
GRÁFICO 1

EVOLUCIÓN DE LA APORTACIÓN DEL TURISMO RECEPTOR Y DE OTROS COMPONENTES DEL TURISMO AL PIB DE LA ECONOMÍA ESPAÑOLA. EN PORCENTAJE SOBRE EL PIB (ESPAÑA=100). TASAS DE VARIACIÓN INTERANUAL DE LA DEMANDA TURÍSTICA Y DEL TURISMO RECEPTOR (2000-2012)

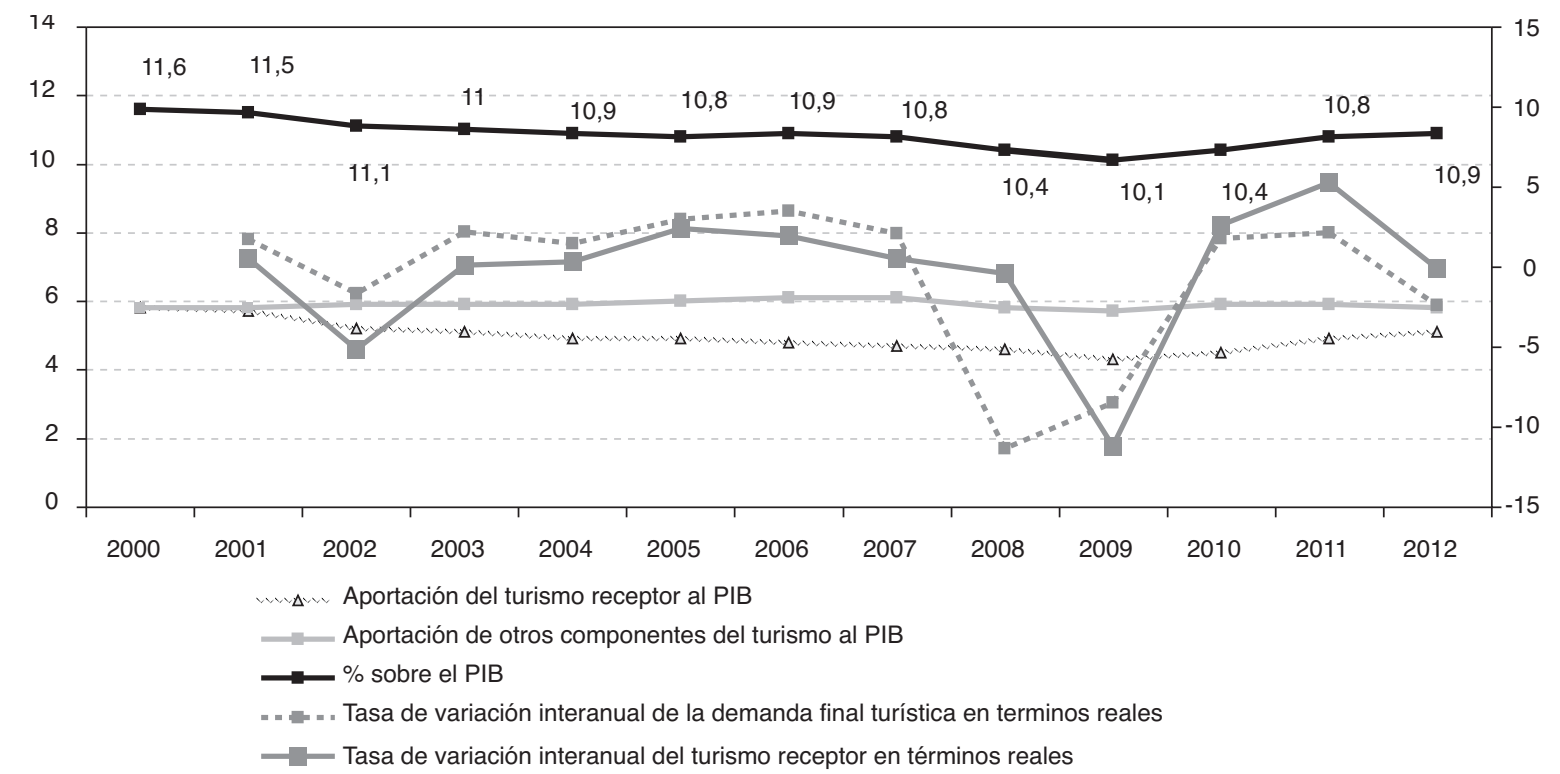

Fuente: eaboración propia a partir de datos de la CSTE. Series 2000-2009 (base 2000) y 2008-2012 (base 2008), y de notas de prensa (2004 a 2013).

medida al aumento de la demanda exterior de nuestros servicios turísticos, parece sugerir que el turismo internacional sigue configurándose como uno de los elementos dinámicos esenciales dentro del conjunto de la economía española.

\section{Análisis de las llegadas de turistas internacionales a España y del gasto realizado}

Para nuestro acercamiento a la evaluación de la importancia de la demanda de turismo internacional en España, en el periodo 2001-2013, se han utilizado los datos relativos a los turistas internacionales recibidos en España según la comunidad autónoma elegida como destino principal y el gasto que esos turistas realizan, a partir de la información proporcionada por la Encuesta de Movimientos Turísticos en Frontera (Frontur) y la Encuesta de Gasto Turístico (Egatur), respectivamente.

El flujo de llegadas de turistas internacionales y visitantes recibidos en España se muestra en el Gráfico 2, incluyendo en los visitantes a los excursionistas recibidos. Ambas variables tienen una evolución creciente a lo largo del periodo considerado. En términos globales los visitantes han experimentado un incremento total de 27,67 millones de personas, es decir un 36,6 por 100 y los turistas un incremento de 12 millones, es decir un 25 por 100. El punto máximo de llegadas de turistas se alcanzó en 2013.

En términos de tasas de crecimiento los valores máximos se alcanzaron en los años 2005 y 2011, con tasas de variación interanuales del 6,6 por 100 en ambos casos, y los valores mínimos se alcanzaron en los años 2008 y 2009 con tasas que fueron incluso negativas $(-2,5$ por 100 y $-8,8$ por 100 , respectivamente). A partir del año 2009, el turismo internacional experimentó un tímido crecimiento, manteniéndose en tasas positivas en los años 2012 y 2013.

Como se ha indicado anteriormente, la información sobre el gasto que realizan los turistas internacionales que recibe nuestro país han sido tomados de Egatur, pues el marco de elevación de los resultados muestrales obtenidos en ella son los datos de visitantes proporcionados por la estadística $\triangle$ 
GRÁFICO 2
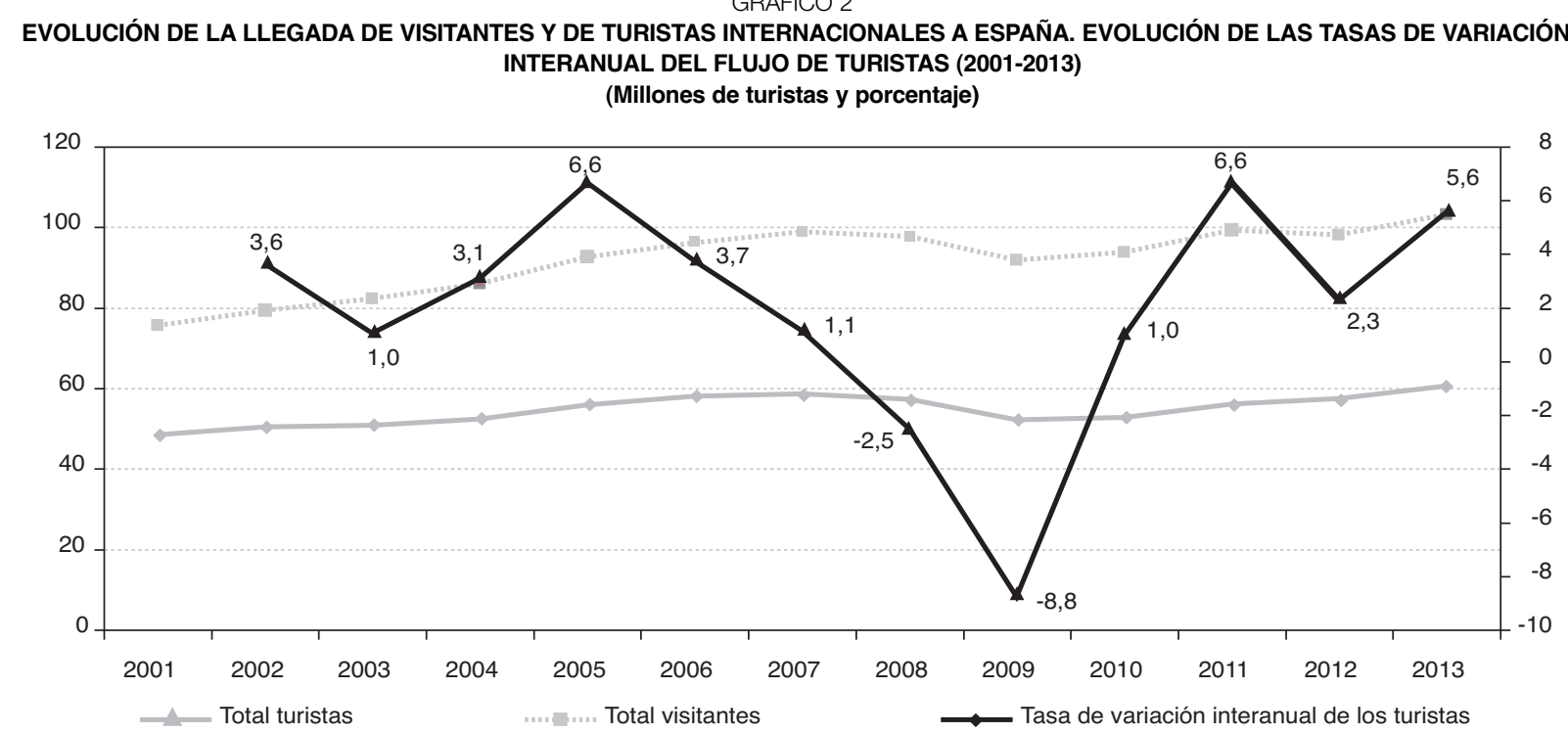

Fuente: Instituto de Estudios Turísticos. Elaboración propia a partir de datos de Frontur ( 2001 a 2013).

Frontur. De hecho, a partir del año 2009, la edición y publicación de los informes anuales de Frontur y Egatur se hace de forma conjunta, ofreciendo así un análisis de datos integrados de la llegada de visitantes internacionales y del gasto que realizan (Egatur, 2004, 2009). Además, la vinculación entre Frontur y Egatur no se limita al procedimiento de elevación de los resultados de esta última, sino que también ambas operaciones estadísticas comparten el soporte técnico, la organización y operativa de control de campo y los lugares de encuesta ${ }^{2}$.

No obstante, este estudio del gasto se ha realizado tan sólo para el periodo de 2003 a 2013, ambos inclusive, dado que por razones metodológicas los datos que existen para los años 2001 y 2002, y que son ofrecidos por Frontur, no son comparables con los datos que ofrece Egatur para los años 2013. En efecto, aunque Egatur dispone de información anterior al año 2003, la modificación del cuestionario realizada en enero de 2004 imposibilita la comparación directa de estos datos con los correspondientes a años posteriores. Por ello, en el Informe Anual de Egatur correspondiente al año 2004 se realiza un enlace para los datos

2 Nota Metodológica (Egatur). del año 2003 con el fin de facilitar la comparación y el análisis de los resultados de 2004. Esa publicación recoge, por tanto, los datos relativos al año 2004 y el enlace del año 2003, no siendo comparable esta información con los datos de gasto publicados con anterioridad a ese informe anual, es decir, con los datos del gasto de los años 2001 y 2002 publicados por Frontur (Egatur, 2004). Para el año 2004 y para el enlace de 2003, Egatur ofrece la información de gasto tanto a precios corrientes como a precios constantes, fijando el año base en 2004, al ser el primer año completo con la información del cuestionario actualmente vigente. Sin embargo, a partir del año 2004 y hasta la actualidad la información del gasto recogida en Egatur se ofrece a precios corrientes (Egatur, 2004 - 2013). Los datos del gasto que se han utilizado han sido pasados a euros constantes del año 2004 y deflactados según el IPC elaborado por el INE ${ }^{3}$.

Se considera gasto turístico total el gasto realizado por el turista o por cuenta del turista durante su viaje a España (Egatur, 2007). El gasto medio por persona es el gasto total realizado por el turista entre el número de turistas llegados a España, y el gasto medio diario o por persona y día, el gasto $\square$

\footnotetext{
3 INE, IPC Base 2011, 2015.
} 

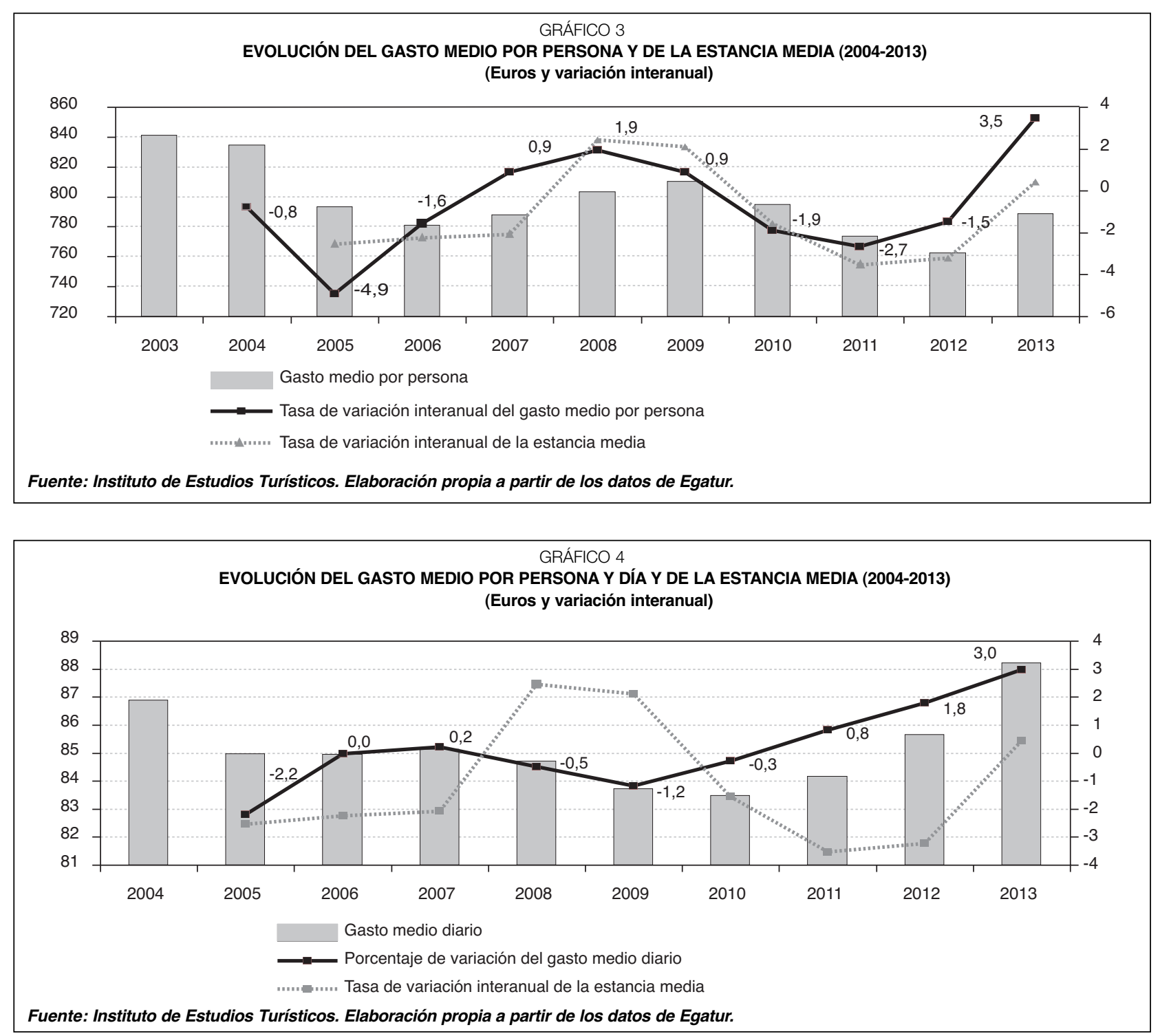

total realizado por el turista entre el número total de pernoctaciones. Este componente del gasto también puede obtenerse dividiendo el gasto medio por persona o turista por la estancia media en el país o duración media del viaje. Entendiendo por estancia media ${ }^{4}$ el número de días que, por término medio, los viajeros permanecen en los establecimientos, calculándose como cociente entre las pernoctaciones y el número de viajeros. Variable en la que la literatura económica sobre la demanda turística cada vez pone más énfasis por su importante capacidad explicativa (Alegre y Pou, 2003) y por

\footnotetext{
${ }^{4}$ La variable estancia media es una aproximación al número de días que, por término medio, los viajeros permanecen en los establecimientos y se calcula como cociente entre las pernoctaciones y el número de viajeros. INE, Encuesta de Ocupación Hotelera, Metodología (2015).
}

constituir un elemento esencial para la determinación del gasto total que el turista internacional realiza en el lugar de destino. Esa estancia o tiempo de permanencia en destino está directamente relacionado con la cantidad de gasto realizado, como muestra el Gráfico 3 para el gasto medio por persona, que sigue una pauta creciente o decreciente en relación directa con los días de estancia media en el periodo considerado.

De igual modo, es posible apreciar un patrón inverso al descrito anteriormente para el gasto medio por persona, es decir, el gasto medio por persona y día disminuye continuamente a medida que la estancia se prolonga y viceversa, como se refleja en la Gráfico 4. 


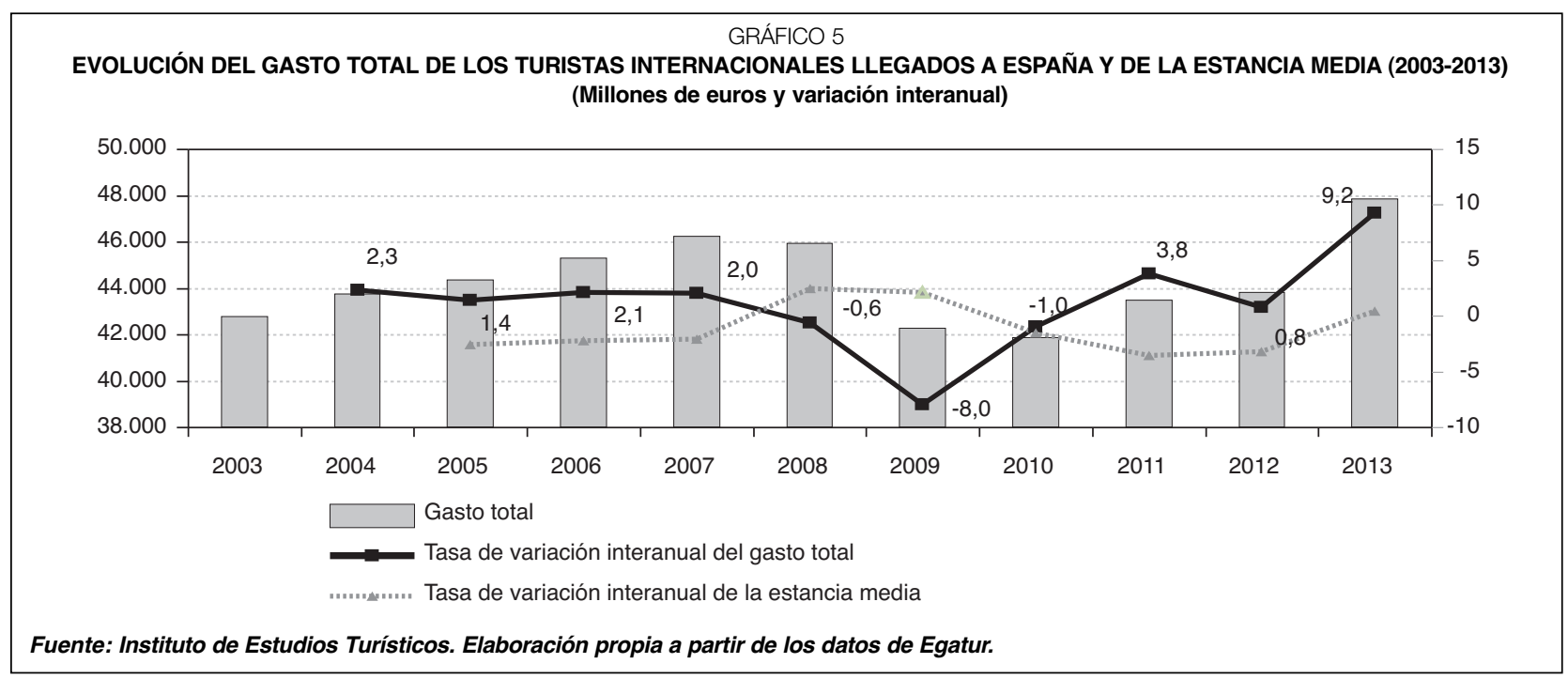

Ambos gráficos muestran que la evolución del gasto es distinta en cada caso para los diferentes tramos de duración de la estancia, es decir, a mayor estancia media mayor gasto medio por persona y menor gasto medio diario. El gasto total también aumenta conforme lo hace la estancia media.

El Gráfico 5, que incorpora la información ya analizada acerca del número de llegadas de turistas internacionales, refleja la evolución del gasto total realizado por los turistas no residentes en España y de su tasa de crecimiento. En términos globales, entre los años 2004 y 2013, la estancia media ha experimentado una reducción de 0,9 días, es decir, de un $-9,98$ por 100 , alcanzando un nivel máximo de 9,9 días en el año 2004 y un nivel mínimo de 8,9 días en el año 2012. Esa evolución global de la estancia media ha determinado que el gasto medio por turista y día se haya incrementado en el periodo 1,3 euros, lo que equivale a una tasa de crecimiento global para todo el periodo de un 1,5 por 100, alcanzando el valor máximo de 88,2 euros en el año 2013 y el valor mínimo de 83,5 euros en 2010.

Las dos variables anteriores han determinado una reducción del gasto medio por turista de 45,8 euros, equivalente a una tasa de variación del $-5,5$ por 100. El valor máximo del gasto medio por turista se alcanzó en el año 2004 con 834,6 euros, mientras que su valor mínimo correspondió al año 2012 con 762,4 euros.
El volumen de llegadas de turistas internacionales en el mismo periodo, como ha sido indicado anteriormente, alcanzó los 9,8 millones de turistas, lo que supuso el 19,3 por 100 de aumento global para el periodo 2004-2013. A consecuencia de esta evolución positiva de las llegadas de turistas, el gasto total ha experimentado un incremento de 5.078 millones de euros, es decir, de un 11,9 por 100, con un nivel mínimo de $41.877,8$ millones de euros en el año 2010 y un máximo de $47.850,7$ millones de euros en 2013.

\section{El turismo cultural (2005-2013)}

Para analizar los datos relativos al segmento del turismo internacional constituido por las llegadas de turistas internacionales que visitan nuestro país motivados por su cultura, y junto a las fuentes de datos ya citadas, se ha utilizado también la información sobre estadísticas de cultura que se elabora en el ámbito del Ministerio de Educación, Cultura y Deporte (MECD), concretamente las ofrecidas por el sistema CULTURABase y por el Anuario de Estadísticas Culturales.

En el Gráfico 6 se muestra la evolución que han tenido, para el periodo 2005-2013, las llegadas de turistas internacionales por motivos culturales. Asimismo se recoge la relación entre las entradas de turistas internacionales que llegan a España $\triangleright$ 


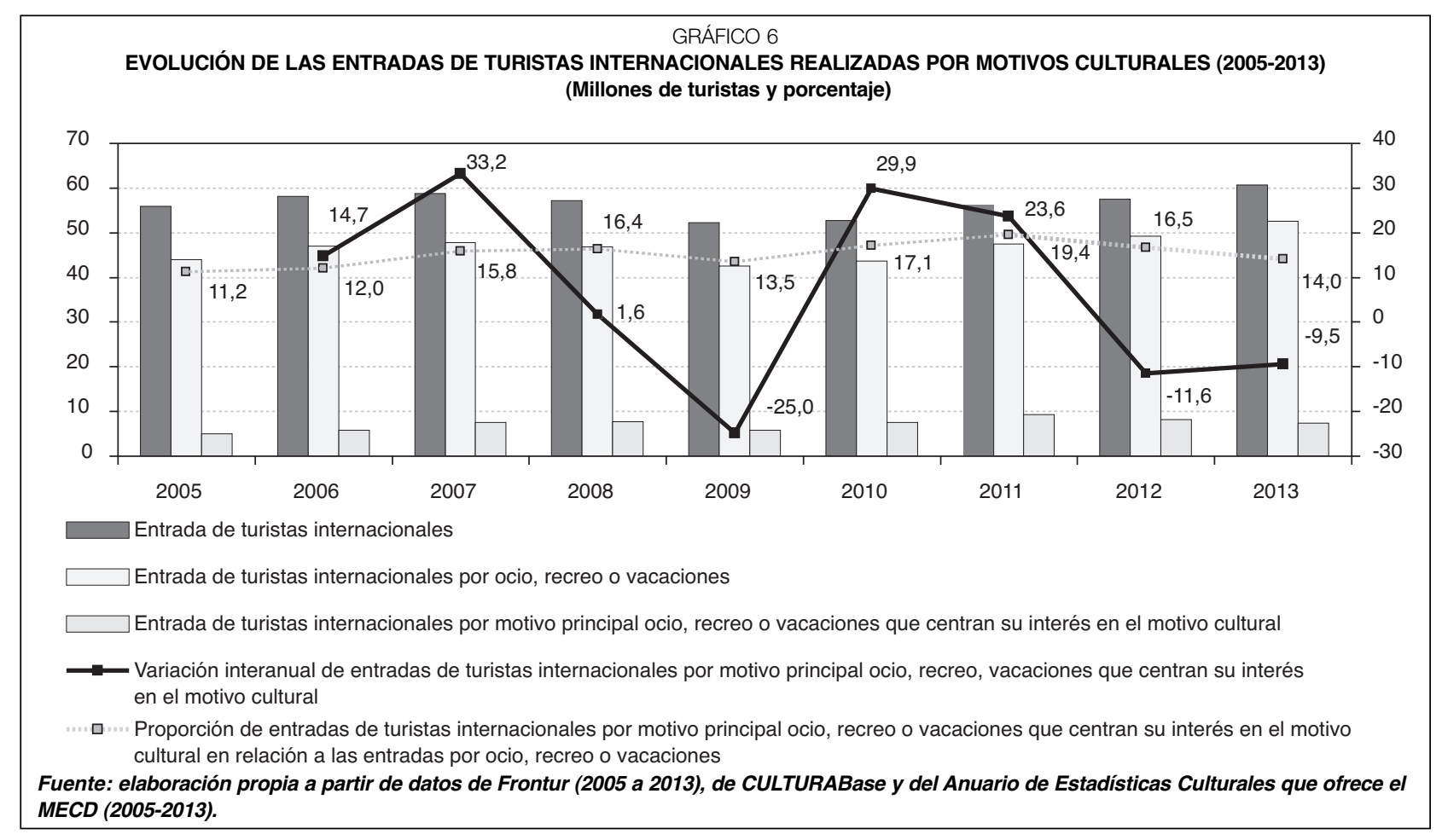

cualquiera que sea el motivo principal de su viaje y aquellos que lo hacen motivados principalmente por razones de ocio, recreo o vacaciones.

Destaca la importancia que ha tenido en todo el periodo estudiado el ocio y las vacaciones, siendo ese el motivo principal por el que han acudido a España la mayor parte de los turistas internacionales. Junto al ocio, recreo o vacaciones, los turistas internacionales llegados a España lo han hecho también por otros motivos principales (trabajo o estudios, y otros motivos como visita a familiares) (Frontur, 2005-2013).

Dentro de los turistas recibidos en nuestro país por motivos de ocio o vacaciones en los años analizados, el mayor porcentaje corresponde a aquellos que han venido con el objetivo del descanso en el campo o la playa, seguidos de los turistas que han centrado su interés en el motivo cultural. Así, en los años estudiados, el porcentaje de turistas que han visitado nuestro país atraídos por su cultura, dentro del total de entradas por ocio, recreo o vacaciones, ha alcanzado valores que oscilan entre el 11,2 por 100 en el año 2005 y el 19,5 por 100 en 2011, como muestra el Gráfico 6. Estas cifras convierten al motivo cultural en el segundo motivo, detrás del sol y playa, por el que los turistas internacionales han visitado España. En términos de tasas de variación, el Gráfico 6 muestra el máximo alcanzado en el año 2007 por este colectivo, con un crecimiento interanual de un 33,2 por 100 , respecto al año 2006, lo que supuso la llegada de 7,5 millones de turistas. A partir de entonces y hasta el año 2009 se desacelera el crecimiento de forma acusada hasta alcanzar valores negativos, como el mínimo del -25 por 100 correspondiente al año 2009. Tras dos años de crecimiento positivo, el año 2010 y el año 2011, con valores que alcanzan el 29,9 por 100 , segundo máximo del periodo, y el 23,6 por 100, respectivamente, el crecimiento de las llegadas de turistas internacionales relacionadas con el motivo cultural decrece de nuevo. Como muestra el Gráfico 6, el peso de esta motivación es la más general de ocio, recreo o vacaciones y registra una participación que ha oscilado entre un valor mínimo del 11,22 por 100 en el año 2005 y un máximo en el año 2011 de un 19,43 por 100, y parece haber perdido importancia en los últimos dos años, hasta contribuir el año 2013 con tan sólo un 14 por 100.

El Gráfico 7 muestra el gasto que han realizado los turistas internacionales llegados a nuestro país $D$ 


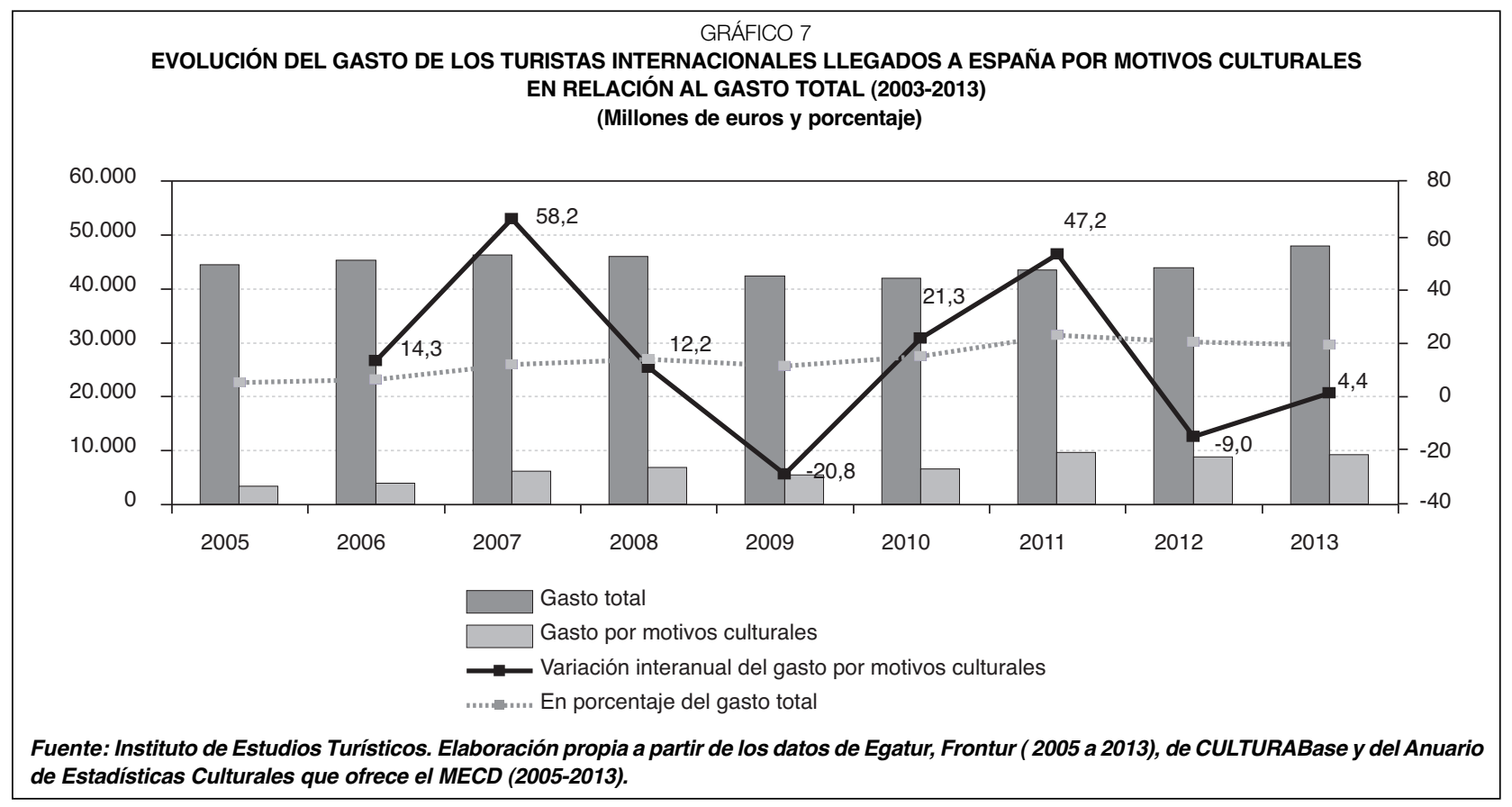

por motivos culturales. Este gasto muestra un comportamiento muy similar al que experimenta el gasto total realizado por el turismo receptor. En términos absolutos sus valores oscilan entre $3.358,7$ millones de euros en el año 2006 y $9.643,0$ millones de euros alcanzados en 2011, año en que se acelera su crecimiento hasta llegar a una tasa del 47,2 por 100 respecto al año anterior, una de las más altas del periodo junto con la del año 2007, en el que creció 43,9 décimas más que en el año 2006. El peso que representa el gasto por motivos culturales, en el gasto total de los turistas internacionales que llegan a nuestro país, sigue una senda prácticamente creciente, con valores comprendidos entre el 7,6 por 100 del año 2005 y el 22,2 por 100 del año 2011.

Junto a los turistas internacionales que han visitado nuestro país motivados fundamentalmente por su cultura, puede resultar igualmente interesante conocer cómo ha sido en estos años la evolución de aquellos que declararon haber realizado algún tipo de actividad durante su estancia en España, cualquiera que fuese la motivación principal del viaje (ocio, recreo o vacaciones, trabajo o estudios, y otros motivos como visita a familiares). Esa evolución, como refleja el Gráfico 8, se mantiene en promedio en torno al 53 por 100, siendo esta participación mínima en los años 2010 y 2012, en los que alcanza un 51,3 por 100 en cada uno, y máxima en el año 2008, con un 55 por 100 de contribución, por lo que en esos años estudiados más de la mitad de los turistas que nos visitaron, con independencia del motivo principal que les llevara a ello, realizaron durante su estancia, entre otras actividades, algún tipo de actividad cultural. En cualquiera de sus manifestaciones (asistencia a espectáculos culturales, visitas culturales, otras actividades culturales) estas actividades fueron las más demandadas por el turismo receptor.

En términos de variación interanual es nuevamente el año 2009 el que marca un claro cambio de tendencia, registrando un crecimiento negativo del $-11,3$ por 100 , respecto del año 2008 , poniendo fin a unos años de acentuada desaceleración en un contexto generalizado de bajadas del número de turistas, y que parece estabilizarse a partir del año 2011, con tasas positivas que rondan un promedio del 6,5 por 100 en los últimos años del periodo.

Un análisis más pormenorizado de estas entradas de turistas internacionales que realizan actividades culturales, se obtiene al desagregar la información estadística contenida en el Gráfico 8 en función de cuál ha sido el motivo principal por el que $\square$ 

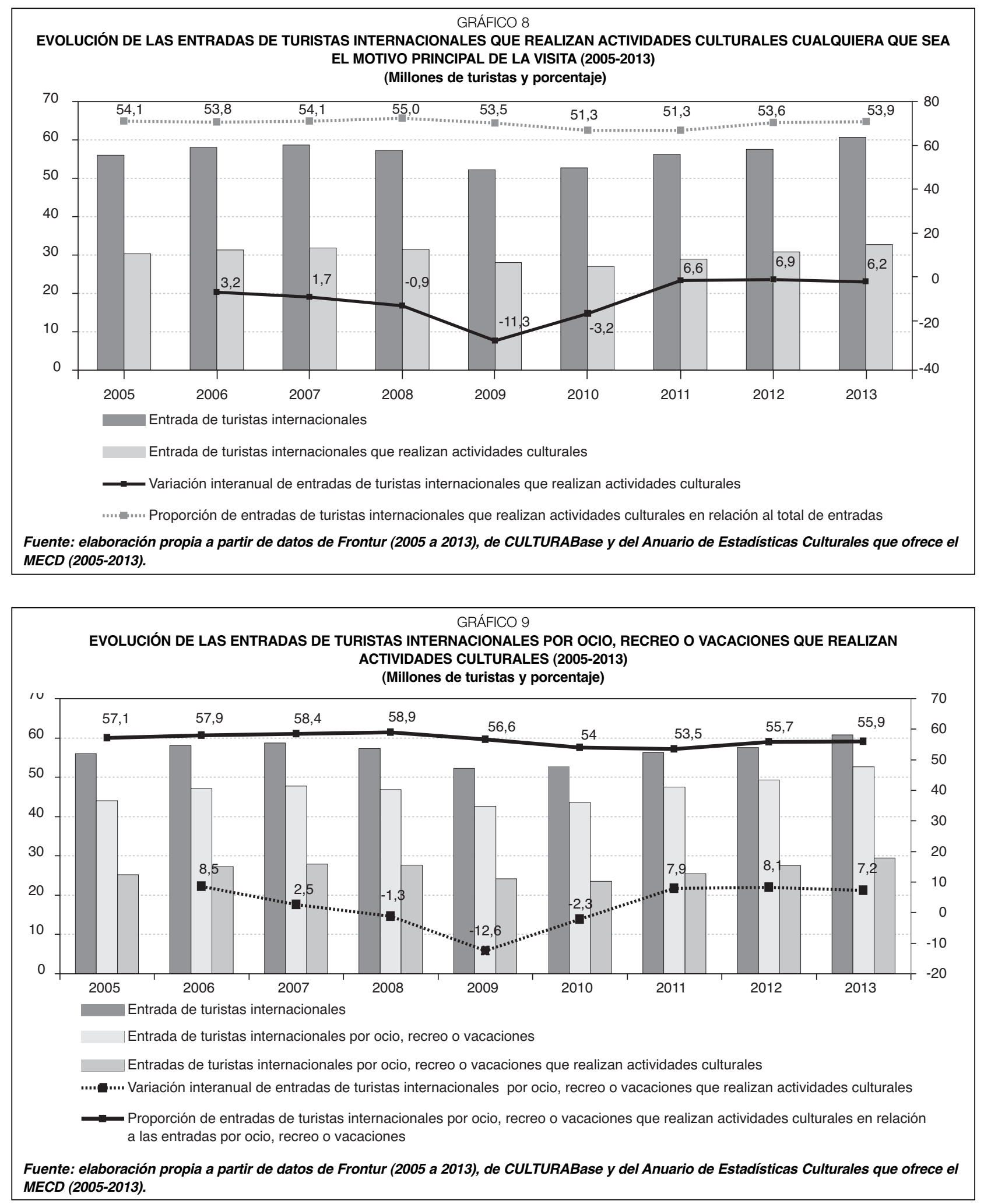

estos turistas han realizado su viaje, lo que se muestra en los Gráficos 9, 10 y 11.

El Gráfico 9 recoge la evolución de las entradas de turistas internacionales que han escogido nuestro país, motivados por el ocio, el recreo o las vacaciones y que, además, han realizado, entre otras, actividades culturales. Destaca considerablemente el peso que alcanza ese colectivo en $\triangleright$ 

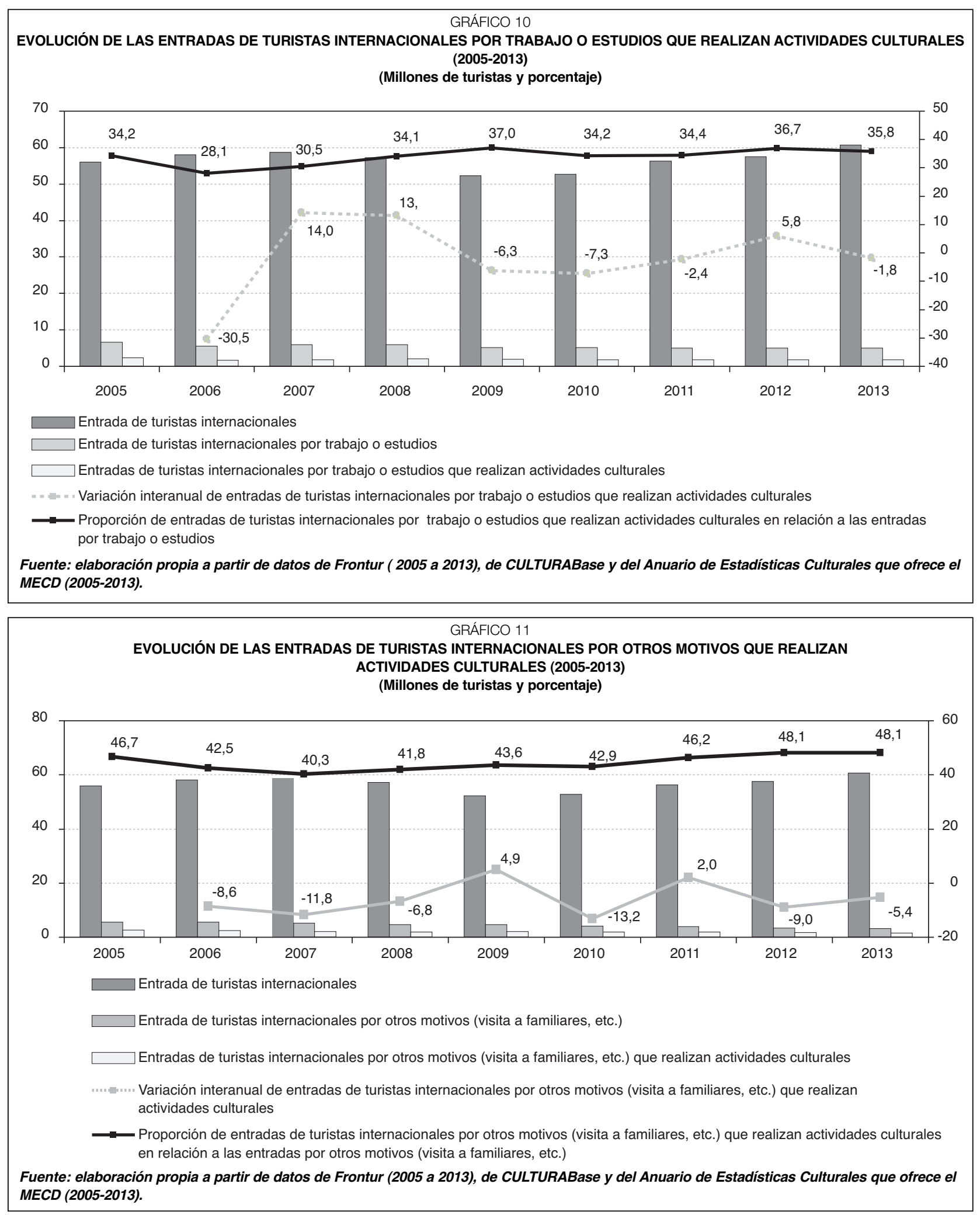

todo el periodo estudiado, con unos valores mínimo y máximo, de un 53,5 por 100 en el año 2011 y de un 58,9 por 100 en el año 2008, respectivamente. El Gráfico 10 se centra en la evolución de las entradas de turistas internacionales que fueron realizadas principalmente por motivos de trabajo 0 de negocios. De este colectivo, un 31 por 100 aprovechó para realizar actividades culturales, con un $\triangleright$ 
rango que oscila entre el 28,1 por 100 del año 2006 y el 37 por 100 del año 2009, año en que se aprecia ya una importante desaceleración en su crecimiento, con tasas negativas que no remontan hasta el año 2012. Finalmente, el Gráfico 11 muestra la evolución de las entradas de turistas internacionales realizadas por motivos distintos a los anteriores, como pueden ser las visitas a los familiares. Estos turistas también realizaron actividades culturales durante su estancia en nuestro país. En este caso, la proporción respecto al total de entradas se reduce considerablemente. El peso de este colectivo en los años estudiados oscila entre el valor mínimo del 40,3 por 100, alcanzado en el año 2007, y el valor máximo del 48,1 por 100 que se repite en los dos últimos años. En términos de tasas de crecimiento, la mayor tasa se registra en el año 2009, en que ésta alcanza el 4,9 por 100 respecto al año anterior.

\section{Conclusiones}

El turismo se ha convertido en una de las actividades económicas más importantes en el ámbito internacional, alcanzando las llegadas de turistas internacionales en 2014 un total de 1.138 millones de personas, con un crecimiento del 4,7 por 100 respecto al año anterior. La actividad turística aportó el 10,9 por 100 del PIB y generó el 11,9 por 100 del empleo total de España en el año 2012. La contribución al PIB del consumo turístico receptor pasó de ser un 4,3 por 100 en el año 2009 a un 4,5 por 100 en 2010 , y de un 4,9 por 100 en 2011, a un 5,1 por 100 en 2012.

Las llegadas de turistas y de visitantes a España muestran un crecimiento continuo a lo largo de todo el periodo considerado (2001-2013).

La estancia media de los turistas internacionales llegados a España se ha mantenido en torno a los 9,4 días durante el periodo analizado. Existe una relación directa y positiva entre el gasto medio por persona y la duración de la estancia media, mientras que el gasto medio diario disminuye continuamente a medida que la estancia se prolonga, y viceversa. A consecuencia de la evolución positiva de las llegadas de turistas, el gasto total ha experimentado un incremento de 5.078 millones de euros, es decir, de un 11,9 por 100.

Las nuevas tipologías de turismo aparecen caracterizadas en buena medida por una mayor sensibilidad por la conservación del medio ambiente. Dentro de esta nueva tendencia cabe destacar el turismo cultural. El ocio, recreo y vacaciones, es el motivo principal por el que han acudido a España la mayor parte de los turistas internacionales. Estos turistas han pasado de ser 43,9 millones en el año 2005 a 52,6 millones en el año 2013. El motivo cultural es el segundo motivo, detrás del sol y playa, por el que se han sentido atraídos los turistas internacionales que han visitado España por el ocio y las vacaciones.

El gasto realizado por motivos culturales muestra un comportamiento muy en sintonía con el que experimenta el gasto total realizado por el turismo receptor. En términos del peso que representa este gasto sigue durante todo el periodo una senda prácticamente creciente, que se mantiene en torno a valores comprendidos entre el 7,6 por 100 del año 2005 y el 22,2 por 100 del año 2011.

Durante los años estudiados la participación de turistas internacionales recibidos en España, que declararon haber realizado algún tipo de actividad cultural durante su estancia en este país cualquiera que fuese el motivo principal del viaje, se mantiene en promedio en torno al 53 por 100 . En cualquiera de sus manifestaciones las actividades culturales fueron las más demandadas por el turismo receptor.

El peso de las entradas de turistas internacionales que han escogido nuestro país, motivados por el ocio, el recreo o las vacaciones y que, además, han realizado, entre otras, actividades culturales, alcanza unos valores mínimo y máximo de un 53,5 por 100 en el año 2011 y de un 58,9 por 100 en el año 2008, respectivamente. El peso de las entradas de turistas internacionales que fueron realizadas principalmente por motivos de trabajo o $D$ 
Mª de la Palma Gómez-Calero Valdés, María del P. Pablo-Romero Gil-Delgado y Javier Sánchez Rivas

de negocios y que, además, han realizado, entre otras, actividades culturales, alcanzó en promedio el 31 por 100. El peso de las entradas de turistas internacionales, realizadas por motivos distintos a los anteriores como pueden ser las visitas a los familiares, que realizaron actividades culturales durante su estancia en nuestro país, oscila entre el valor mínimo del 40,3 por 100 alcanzado en el año 2007 y el valor máximo del 48,1 por 100 , que se repite en los dos últimos años.

\section{Bibliografía}

[1] ALEGRE, J. y POU, L. (2003). La estancia media de los turistas en las Islas Baleares: determinantes microeconómicos e implicaciones sobre la evolución del gasto agregado. X Simposio Internacional de Turismo y Ocio de ESADE: Barcelona.

[2] INSTITUTO NACIONAL DE ESTADÍSTICA (2010). Cuenta Satélite del Turismo de España. Base 2000, Serie 2000-2009. Madrid.

[3] INSTITUTO NACIONAL DE ESTADÍSTICA (2013). Cuenta Satélite del Turismo de España. Base 2008, Serie 2008-2012. Madrid.

[4] INSTITUTO NACIONAL DE ESTADÍSTICA (2013). Encuesta de Ocupación Hotelera. Metodología. Madrid.
[5] INSTITUTO NACIONAL DE ESTADÍSTICA (2015). Índice de Precios de Consumo (IPC), Base 2011. Madrid.

[6] MINISTERIO DE EDUCACIÓN, CULTURA Y DEPORTE (2005-2013). Anuario de Estadísticas Culturales. Madrid.

[7] MINISTERIO DE EDUCACIÓN, CULTURA Y DEPORTE (2005-2013). CULTURAbase. Notas metodológicas. Madrid.

[8] INSTITUTO DE ESTUDIOS TURÍSTICOS (20012013). Encuesta de Movimientos Turísticos en Frontera (Frontur). Madrid.

[9] INSTITUTO DE ESTUDIOS TURÍSTICOS (20042013). Encuesta de Gasto Turístico (Egatur). Madrid.

[10] INSTITUTO DE ESTUDIOS TURÍSTICOS (20042013). Encuesta de Gasto Turístico (Egatur): Nota Metodológica. Madrid.

[11] ORGANIZACIÓN MUNDIAL DEL TURISMO (2010). Recomendaciones internacionales para Estadísticas de Turismo, 2008. Serie $\mathrm{M}, \mathrm{n}^{\circ} 83$ (Rev-1.0). Madrid, Nueva York.

[12] ORGANIZACIÓN MUNDIAL DEL TURISMO (2015). Barómetro del Turismo Mundial, Anexo estadístico. Madrid.

[13] ORGANIZACIÓN MUNDIAL DEL TURISMO. (2010). Cuenta satélite de turismo: recomendaciones sobre el marco conceptual, 2008. Series F, $n^{\circ} 80$ (Rev-1). Comisión de las Comunidades Europeas, Eurostat. Organización de Cooperación y Desarrollo Económicos: Luxemburgo, Madrid, New York, París. 